\title{
Coronary Arteriographic Profile in Hypertrophic Cardiomyopathy
}

\author{
ATM IQBAL HASAN, HARISUL HAQUE, M. MUSTAFAZAMAN, KMHS SIRAJUL HAQUE, \\ SAJAL KRISHNA BANERJEE, MD. ABU SIDDIQUE, JAHANARAARZU, MD. ASHRAF UDDIN SULTAN, \\ NAVEEN SHEIKH, MARIA, MOLLIK, MA MUQUEET
}

Department of Cardiology, Bangabandhu Sheikh Mujib Medical University, Dhaka, Bangladesh

Address of Correspondence: Dr. ATM Iqbal Hasan, Associate Professor, Department of Cardiology, BSMMU

Dhaka, Bangladesh, E-mail: driqbal27@gmail.com

\begin{abstract}
Back Ground: Hypertrophic cardiomyopathy is genetically transmitted primary cardiac disease and an important cause of morbidity and sudden death in young people, including competitive athletes.

Objectives: The study was designed to compare the CAG findings between normal subject and hypertrophic cardiomyopathy patients who required $C A G$

Methods: HCM was diagnosed by using diagnostic criteria (clinical, electrocardiography and echocardiography) defined by Western Working group. The study was carried out on 60 subjects of which 30 had hypertrophic cardiomyopathy, 30 age and sex control (normal subjects).

Results: In comparison of control it was observed that HCM cases had significantly larger proximal left anterior descending (3.81+-0.64 vs 2.49+-0.61 P<0.001), proximal left circumflex (3.29+-0.46 Vs 2.39+-0.60, $p<0.001)$ and proximal right coronary artery $(3.15+-0.47$ vs $2.49+-0.42, P<0.001)$. Coronary artery stenosis were found in 5 cases of HCM and among them, single vessel disease was present in 3, double vessel disease in I and triple vessel disease in I cases.

Conclusion: Coronary artery disease (CAD) associated with hypertrophic cadiomyopathy (HCM) is a complex clinical syndrome, difficult to diagnose clinically, that can reliably be recognized by coronary arteriography.
\end{abstract}

\section{Introduction:}

Hypertrophic cardiomyopathy is genetically transmitted primary cardiac disease and an important cause of morbidity and sudden death in young people, including competitive athletes. At present, however, few data exists to estimate the prevalence of this disease in large population. The prevalence of HCM appears to be about 0.2 percent on general population and 0.5 percent in primary medical practice based on identification of the disease phenotype with two-dimensional echocardiography (2D-echo) (Maron et al., 1995).

Abnormal electrocadiographic (ECG) findings are usual in early stage of HCM and this observation is, therefore, important in its early detection. Echocardiography remains the single most important diagnostic test for HCM. HCM was diagnosed by using the diagnostic criteria (echo, ECG) defined the Western Working Group (McKenna et al., 1997).

Ischemia is suspected to occur frequently in patients with HCM and may result from various mechanisms, for example, decreased coronary flow reserve, disease of small intramuscular arteries, inadequate size of coronary arteries relative to hypertrophied myocardium, diminution of coronary blood flow during systole, coronary artery spasm and coexistent atherosclerotic coronary artery disease (CAD), which can be present in up to a quarter of HCM patients above 45 years of age. Diagnosis of CAD in patients with $\mathrm{HCM}$ to difficult to make on clinical grounds, secondary to the high frequency of angina in patients with HCM without CAD. Pharmacological stress echocardiography is promising but needs to be further studied; stress thallium imaging is best with frequent false positive result. At this time, coronary angiography remains the only reliable test for definitive diagnosis of coexistent CAD in HCM (Harjai et al., 1996).

Kaufmanns et al. (1996) found in their study that coronary artery size increases as left ventricular mass increases in HCM, but size of the coronary arteries is inappropriate with regard to left ventricular hypertrophy. Thus, the stimulus for growth of the coronary arteries is not influenced by the underlying disease but appears to depend on the degree of left ventricular hypertrophy (Kaufman et al., 1996).

\section{Diagnostic Criteria}

The proposed diagnostic criteria for establishing a diagnosis of hypertrophic cardomyopathy are as follows. The diagnosis established by the presence of one major 
criterion, two minor echocardiographic criteria, or one minor echocardiographic and two minor electrocardiographic criteria (McKenna et al., 1997).

\section{Echocardiography:}

Major criteria

- Left ventricular wall thickness e"13 $\mathrm{mm}$ in the anterior septum or posterior wall e" $15 \mathrm{~mm}$ in the posterior septum or free wall.

- Severe systolic anterior motion of the mitral valve (septal-leaflet contact).

\section{Minor criteria}

- left ventricular wall thickness $12 \mathrm{~mm}$ in the anterior septum or posterior wall, or of $14 \mathrm{~mm}$ in the posterior septum or free wall.

- Moderate systolic anterior motion of the mitral valve (no leaflet-septal contact).

- Redundant mitral valve leaflets.

\section{Electrocardiography}

\section{Major criteria}

- LVH plus repolarization changes (Romhilt and Estes).

- T wave inversion in leads I and aVL (e" $3 \mathrm{~mm}$ ), with QRS-T wave axis difference e" 30 degree, V3- V6 (e" 3 $\mathrm{mm}$ ) or II and III and aVF (e" $5 \mathrm{~mm}$ )

- Abnormal Q ( $>40$ ms of $>25$ percent $\mathrm{R}$ wave) in at least two leads from II, III, aVF (in absence of left anterior hemiblock), V1-V4 or I, aVL, V5- V6.

\section{Minor criteria}

- Complete bundle branch block or (minor) intraventricular conduction defect (in LV leads).

- Minor repolarization changes in left ventricular leads.

- Deep S V2 (>25 mm).

- Unexplained chest pain, dysponea of syncope.

\section{Methods:}

This prospective study was carried out in the Department of Cardiology, Bangabandhu Sheikh Mujib Medical University (BSMMU) and Combined Military Hospital (CMH), Dhaka, during the period of April 2000 to November 2001. This cross-sectional prospective study was carried out on 60 subjects, of which 30 had hypertrophic cardomyopathy and 30 age and sex matched control. Informed contents were obtained from each of the study patient.

\section{Inclusion criteria}

Control $(\mathbf{n}=\mathbf{3 0})$

1) Subjects presenting with chest pain, equivocalnegative exercise studies.

2) Who had no valvular or congenital heart disease of left ventricular hypertrophy.

3) Who had normal coronary arteriography.

4) Those who underwent coronary arteriography.

\section{Case $(n=30)$}

1) Patients presenting with unexplained chest pain, dysponea or syncope.

2) Hypertrophic cardiomyopathy diagnosed using diagnostic criteria (clinical, echocardiography, electrocardography) defined by Western Working Group (McKenna et al., 1997).

3) Patients who underwent coronary arteriography.

\section{Exclusion criteria}

Case $(\mathbf{n}=30)$

1) Thickening of left ventricular wall associated with hypertension.

2) Patients with congenital heart disease.

3) Patient with valvular heart disease.

4) Known patients of coronary artery disease.

5) Patients unwilling to participate in the study.

\section{Hypertrophic cardiomyopathy (HCM)}

HCM was diagnosed by using diagnostic criteria (clinical, electrocardiography and echocardiography) defined by Western

Working group (McKenna et al., 1997).

\section{Electrocardiographic study}

In al patients standard 12-lead electrosensors were recorded on the date of clinical evaluation, by using limb leads, augmented unipolar leads and unipolar chest leads from V1- V6 at a paper speed of $25 \mathrm{~mm} / \mathrm{sec}$. The electrocadiograms were studied carefully with special reference to the points shown in the ECG diagnostic criteria defined by Western Working Group (McKenna et al., 1997).

\section{Echocardiographic study}

Two-dimensional, M-mode echocardiography with Doppler ultrasound examination were performed with ALOKA SERIES -5000, SYSTEM-5 GEVINGMED. 
Transducer of 3.5 MHz were used for echocardiographic studies. The echocardiograms were studied carefully with special reference to the points shown in the echo diagnostic criteria defined by Western Working Group (McKenna et al., 1997).

\section{Procedure for coronary arteriography}

Coronary arteriography and where needed left ventriculography were done in all patients by standard Judkin's technique through femoral approach by modified Seldinger technique. All antianginal (vasoactive) medications were discontinued for 24 hours. Routine premedication consisted of oral diazepam $(10 \mathrm{mg})$, with avoidance of nitroglycerine ( $>2$ hours). A nonionic contrast material (iopamiro-370) was used for coronary arteriography to minimize hyperemic reactions with transient changes in coronary blood flow (Hess et al., 1980). The prerequisites for CAG were followed according to hospital protocol (Deligonal et al 1995).

\section{Quantitative coronary arteriography}

Quantitative evaluation of coronary arteriograms was performed with a semiautomatic computer system (Bucim et al., 1990). For each vessel segment, two to three enddiastolic measurements in different projections were carried out and averaged to correct for biologic variations in coronary artery dimensions (Suter et al., 1992). Multiangled standard views including anteroposterior (AP), left anterior oblique (LAO), LAO cranial, LAO caudal (spider) and straight left lateral for left coronary system; and right anterior oblique (RAO), LAO and RAO cranial and LAO cranial for right coronary artery were recorded for analysis.

Proximal coronary diameters of the three major coronary vessels (left anterior. left circumflex and right coronary artery) were measured in all patients by using an automatic edge detection programme. We identified vessel edges. Absolute coronary diameters were calculated by the performance of an identical quantitative programme or the angiographic catheter of known dimensions (Cordis $7 \mathrm{Fr}$, $2.33 \mathrm{~mm}$ ) (Spears et al., 1983). Proximal coronary diameters of he left anterior descending and left circumflex arteries were defined as the vessel segment immediately beyond the bifurcation of the left main coronary artery over a length of $\sim 1 \mathrm{~cm}$. The computed traced this segment automatically and calculated the mean diameter over this segment. The proximal diameter of the right coronary artery was defined as the vessel segment $1-2 \mathrm{~cm}$ distal to the coronary ostium. A vessel segment was analyzed over a length of $\sim 1 \mathrm{~cm}$ and the mean diameter was calculated as for the left coronary artery (Brown et al., 1997).

\section{Definitions:}

Normal coronary artery: Angiographically at the epicardial coronary arteries should be clearly visible and there should be no stenosis even nonsignificant and no irregularities of ectasis.

Diseased (obstructed) coronary artery: Angiographically more than 50 percent narrowing of the luminal diameter of any visible coronary artery should be taken as diseased. Angiographically less than 50 percent narrowing of luminal diameter of any visible coronary artery taken as nonsignificant CAD. Left main coronary artery stenosis should be taken when there is stenosis of left main coronary artery. Single- vessel disease (SVD) should be taken when there is stenosis either left anterior descending (LAD) or left circumflex (LCx) or right coronary artery (RCA). Double-vessel disease (DVD) should be taken when there are stenosis of any two of three (LAD, LCx, RCA) vessels. Triple-vessel disease (TVD) should be taken when there are stenosis of all three vessels (LAD, LCx and RCA) (Deligonal et al., 1995).

\section{Results:}

This prospective study was carried out at BSMMU and $\mathrm{CMH}$, Dhaka, during the period of April, 2000 to November, 2001. A total number of 60 subjects were equally divided into control (normal coronary arteriography) and case (HCM diagnosed by criteria defined by Western Working Group, McKenna et al., 1997). All 60 subjects of this study underwent coronary arteriography.

Table-I

Characteristics of the study subjects

\begin{tabular}{|c|c|c|c|c|}
\hline Parameters & \multicolumn{2}{|c|}{ Control (n=30) } & \multicolumn{2}{|c|}{ Case $(n=30)$} \\
\hline Age (years) (mean \pm SD) & \multicolumn{2}{|c|}{$44.35 \pm 15.14$} & \multicolumn{2}{|c|}{$45.00 \pm 15.38$} \\
\hline \multicolumn{5}{|l|}{$\operatorname{Sex}($ No. $/ \%)$} \\
\hline Male & 27 & $(90.0)$ & 27 & $(90.0)$ \\
\hline Female & 3 & $(10.0)$ & 3 & $(10.0)$ \\
\hline
\end{tabular}


Table-II

Distribution of risk factors

\begin{tabular}{|c|c|c|c|c|c|c|}
\hline \multirow[t]{2}{*}{ Risk factors } & \multicolumn{2}{|c|}{$\begin{array}{c}\text { Control } \\
(\mathrm{n}=30)\end{array}$} & \multicolumn{2}{|c|}{$\begin{array}{c}\text { HCM with } \\
\text { normal coronary } \\
\text { artery } \\
(\mathrm{n}=25)\end{array}$} & \multicolumn{2}{|c|}{$\begin{array}{c}\text { HCM with } \\
\text { abnormal coronary } \\
\text { artery } \\
(\mathrm{n}=5) \\
\end{array}$} \\
\hline & No. & $(\%)$ & No. & $(\%)$ & No. & $(\%)$ \\
\hline Smoking & 12 & $(40.00)$ & 7 & $(28.00)$ & 4 & $(80.00)$ \\
\hline Current & 10 & & 5 & & 4 & \\
\hline Past & 2 & & 2 & & 0 & \\
\hline Diabetes mellitus & 2 & $(6.67)$ & 2 & $(8.00)$ & 4 & $(80.00)$ \\
\hline Dyslipidaemia & 5 & (16.67) & 4 & (16.00) & 5 & (100.00) \\
\hline $\begin{array}{l}\text { Family history of } \\
\text { coronary artery } \\
\text { disease (CAD) }\end{array}$ & 5 & (16.67) & 2 & $(8.00)$ & 2 & $(40.00)$ \\
\hline
\end{tabular}

Table-III

Comparison of risk factors between control and HCM cases with normal coronary artery

\begin{tabular}{lcccccc}
\hline & \multicolumn{2}{c}{$\begin{array}{c}\text { HCM with } \\
\text { Control } \\
\text { Risk factors }\end{array}$} & \multicolumn{2}{c}{$\begin{array}{c}\text { Hormal coronary } \\
\text { artery } \\
(\mathrm{n}=25)\end{array}$} & P value \\
\cline { 2 - 6 } & No. & $(\%)$ & & No. & $(\%)$ \\
\hline Smoking & 12 & $(40.00)$ & & 7 & $(28.00)$ & NS \\
Diabetes mellitus & 2 & $(6.67)$ & & 2 & $(8.00)$ & NS \\
Dyslipidaemia & 5 & $(16.67)$ & & 4 & $(16.00)$ & NS \\
$\begin{array}{l}\text { Family history of coronary artery } \\
\text { disease (CAD) }\end{array}$ & 5 & $(16.67)$ & & 2 & $(8.00)$ & NS \\
\hline
\end{tabular}

\section{Table-IV}

Distribution of ECG parameters of he study subjects

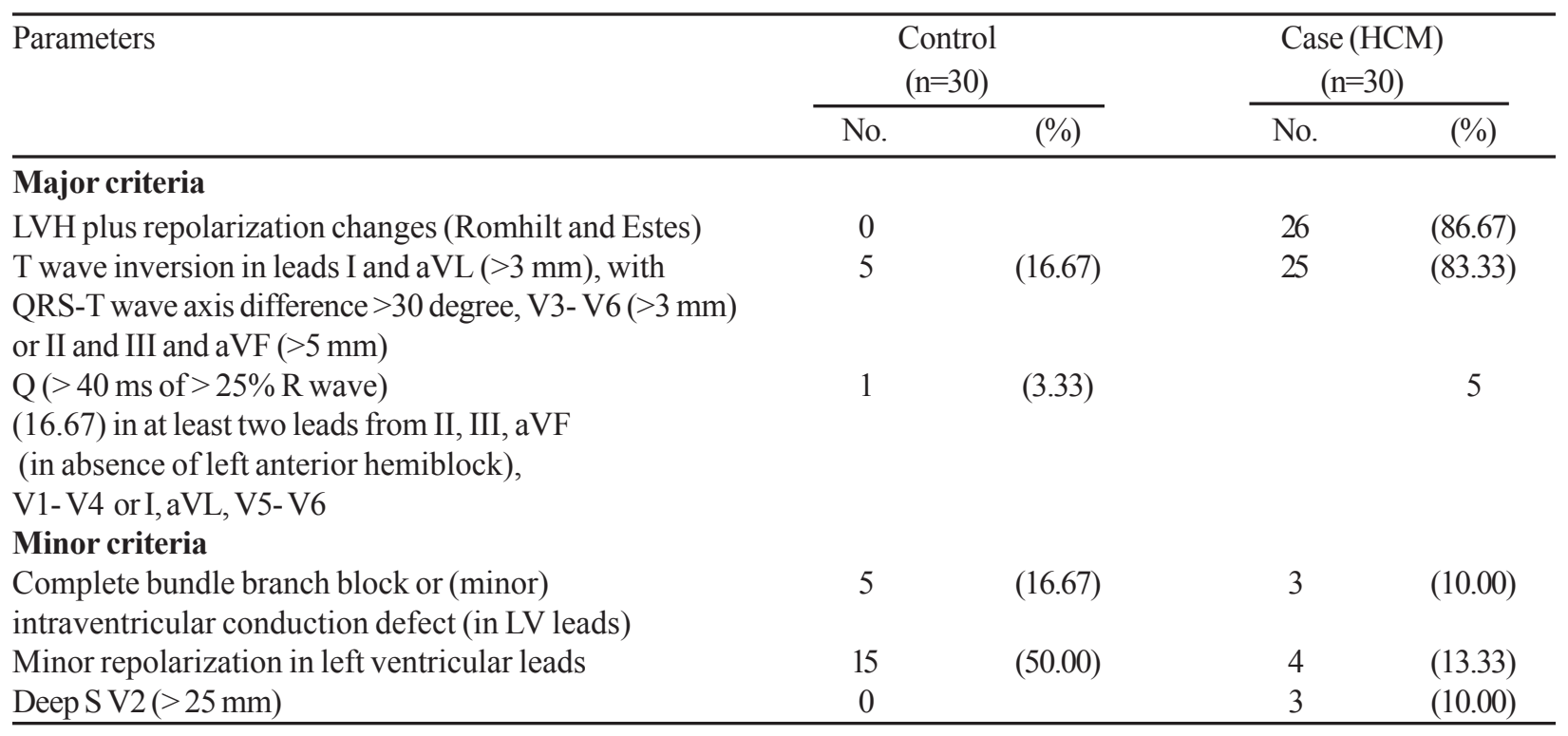


Table-V

Distribution of echo parameters of study subjects

\begin{tabular}{|c|c|c|c|c|}
\hline \multirow[t]{2}{*}{ Parameters } & \multicolumn{2}{|c|}{$\begin{array}{l}\text { Control } \\
(\mathrm{n}=30)\end{array}$} & \multicolumn{2}{|c|}{$\begin{array}{c}\text { Case (HCM) } \\
(\mathrm{n}=30)\end{array}$} \\
\hline & No. & $(\%)$ & No. & $(\%)$ \\
\hline \multicolumn{5}{|l|}{ Major criteria } \\
\hline $\begin{array}{l}\text { LVH ventricular wall thickness }>13 \mathrm{~mm} \text { in the anterior } \\
\text { septum or posterior wall, or }>15 \mathrm{~mm} \text { in the posterior } \\
\text { septum or free wall }\end{array}$ & 0 & & 29 & $(96.67)$ \\
\hline $\begin{array}{l}\text { Severe systolic anterior motion of mitral valve } \\
\text { (septal-leaflet contact) }\end{array}$ & 0 & & 6 & $(20.00)$ \\
\hline \multicolumn{5}{|l|}{ Minor criteria } \\
\hline $\begin{array}{l}\text { Left ventricular wall thickness of } 12 \mathrm{~mm} \text { in the anterior } \\
\text { septum or posterior wall, or of } 14 \mathrm{~mm} \text { in the posterior } \\
\text { septum or free wall }\end{array}$ & 1 & $(3.33)$ & 1 & $(3.33)$ \\
\hline $\begin{array}{l}\text { Moderate systolic anterior motion of mitral valve } \\
\text { (no septal-leaflet contact) }\end{array}$ & 0 & & 18 & $(60.00)$ \\
\hline Redundant mitral valve leaflets & 0 & & 0 & \\
\hline \multicolumn{5}{|l|}{ Others: } \\
\hline $\begin{array}{l}\text { Intraventricular septum/left ventricular } \\
\text { posterior wall ratio }\end{array}$ & 1.04 & & 1.64 & \\
\hline Mild-systolic closure of aortic valve & 0 & & 3 & $(10.00)$ \\
\hline Diastolic dysfunction by Doppler echo & 3 & $(10.00)$ & 24 & $(80.00)$ \\
\hline Ejection fraction $\%($ mean $\pm \mathrm{SD})$ & \multicolumn{2}{|c|}{$58.0 \pm 5.0$} & \multicolumn{2}{|c|}{$72.0 \pm 6.5$} \\
\hline
\end{tabular}

Table-VI

Haemodynamic and left ventricular angiographic data

\begin{tabular}{lccc}
\hline Parameters & $\begin{array}{c}\text { Control }(\mathrm{n}=12) \\
(\text { Mean } \pm \text { SD) }\end{array}$ & $\begin{array}{c}\text { Case }(\mathrm{n}=14) \\
(\text { Mean } \pm \text { SD) }\end{array}$ & P value $^{\mathrm{a}}$ \\
\hline LVSP $(\mathrm{mmHg})$ & $110.0 \pm 20.0$ & $130.0 \pm 32.00$ & $<0.05^{*}$ \\
LVEDP(mmHg) & $8.0 \pm 3.0$ & $21.0 \pm 8.00$ & $<0.01^{*}$ \\
EF $(\%)$ & $60.0 \pm 4.0$ & $70.0 \pm 8.0$ & $<0.05^{*}$ \\
MR & 0 & 3 & \\
RWMA & 0 & 2 & \\
\hline
\end{tabular}


Table-VII

Qualitative coronary angiographic data

\begin{tabular}{|c|c|c|c|c|}
\hline \multirow[t]{2}{*}{ Parameters } & \multicolumn{2}{|c|}{$\begin{array}{c}\text { Control } \\
(\mathrm{n}=30)\end{array}$} & \multicolumn{2}{|c|}{$\begin{array}{c}\text { Case }(\mathrm{HCM}) \\
(\mathrm{n}=30)\end{array}$} \\
\hline & No. & $(\%)$ & No. & $(\%)$ \\
\hline Origin of coronary artery & Normal & & Norma & \\
\hline \multicolumn{5}{|l|}{ Dominant vessel } \\
\hline Right & 26 & $(86.67)$ & 23 & $(76.67)$ \\
\hline Left & 3 & $(10.00)$ & 4 & $(13.33)$ \\
\hline Codominant & 1 & $(3.33)$ & 3 & $(10.00)$ \\
\hline Myocardial bridging & 0 & & 1 & $(3.33)$ \\
\hline Coronary artery stenosis & 0 & & 5 & $(16.67)$ \\
\hline \multicolumn{5}{|l|}{ Severity of CAD among 5 cases: } \\
\hline Single-vessel disease (SVD) & & & 3 & $(60.00)$ \\
\hline Double-vessel disease (DVD) & & & 1 & $(20.00)$ \\
\hline Triple-vessel disease (TVD) & & & 1 & $(20.00)$ \\
\hline
\end{tabular}

Table-VIII

Comparison quantitative coronary arteriographic data between control and case

\begin{tabular}{lccc}
\hline Variables & $\begin{array}{c}\text { Control } \\
(\mathrm{n}=30) \\
(\mathrm{Mean} \pm \mathrm{SD})\end{array}$ & $\begin{array}{c}\text { Case }(\mathrm{HCM}) \\
(\mathrm{n}=30) \\
(\mathrm{Mean} \pm \mathrm{SD})\end{array}$ & P value $^{\mathrm{a}}$ \\
\hline Coronary arteries & & & \\
dimension (mm)1 & & & \\
$\quad$ Proximal LAD & $2.49 \pm 0.61$ & $3.81 \pm 0.64$ & $<0.001^{*}$ \\
$\quad$ Proximal LCx & $2.39 \pm 0.60$ & $3.29 \pm 0.46$ & $<0.001^{*}$ \\
$\quad$ Proximal RCA & $2.49 \pm 0.42$ & $3.15 \pm 0.47$ & $<0.001^{*}$ \\
LAD/ LCx ratio & $1.05 \pm 0.09$ & $1.16 \pm 0.14$ & $<0.001^{*}$ \\
IVS/ LAD ratio & $3.16 \pm 0.36$ & $4.75 \pm 0.73$ & $<0.001^{*}$ \\
IVS thickness (mm) & $7.70 \pm 1.37$ & $17.97 \pm 3.12$ & $<0.001^{*}$ \\
\hline
\end{tabular}

\section{Discussion:}

Coronary arteriography remains the only reliable test to know the coronary arteiographic profile in HCM.

This cross-sectional prospective study was carried out on 60 subjects, of which 30 had hypertrophic cardiomyopathy and age 30 and sex matched control. In both the groups, 90 percent were male and 10 percent female. Mean $( \pm \mathrm{SD})$ age were $45.00 \pm 15.38$ and $44.35 \pm 15.14$ years, respectively, in HCM cases and control.

Twelve (40\%) of control, 7 (28\%) of HCM with normal coronary artery and $4(80 \%)$ of HCM with abnormal coronary artery were smokers. Diabetes mellitus was found in $2(6.67 \%)$ control, $2(8 \%) \mathrm{HCM}$ cases with normal coronary artery and $4(80 \%) \mathrm{HCM}$ cases with abnormal coronary artery. Dyslipidaemia was present in $5(16.67 \%)$ control, $4(16 \%) \mathrm{HCM}$ cases with normal coronary artery and $5(100 \%) \mathrm{HCM}$ cases with abnormal coronary artery. Family history of CAD was found in $5(16.67 \%)$ control, 2 (8\%) HCM cases with normal coronary artery and $2(40 \%)$ HCM cases with abnormal coronary artery. Comparison of risk factors between control and HCM cases with normal coronary artery was statistically no significant. Diabetes mellitus and dyslipidaemia were more common in $\mathrm{HCM}$ cases with abnormal coronary artery than control $(\mathrm{P}<0.01$ and $P<0.001$. respectively). Smoking and family history of CAD were not statistically significant when compared between the two groups. In HCM with abnormal coronary artery age, smoking, diabetes mellitus and dyslipidaemia were significant higher than HCM with normal coronary artery $(\mathrm{P}<0.05, \mathrm{P}<0.05, \mathrm{P}<0.01$ and $\mathrm{P}<0.001$, respectively). There was no significant difference for positive family history of CAD between the two groups. 
HCM cases had significantly higher left ventricular systolic pressure $(130.00 \pm 32.0$ vs $110.00 \pm 20.00 \mathrm{mmHg}, \mathrm{P}<$ $0.05)$, higher left ventricular end-diastolic pressure (21.0 $0 \pm 8.0$ vs $8.0 \pm 3.0 \mathrm{mmHg}, \mathrm{p}<0.01)$ and more ejection fraction $(70.0 \pm$ 8.0 vs $60.0 \pm 4.0, \mathrm{P}<0.05)$ then control. Mitral regurgitation was found in 3 regional wall motion abnormalities in 2 $\mathrm{HCM}$ cases.

Origin of coronary artery both in control and HCM cases were normal. Twenty-six (86.67\%) right dominant, 3 (10\%) left dominant and I (3.33\%) co-dominant coronary vessels were among control group. Twenty-three $(76.67 \%)$ right dominant, $4(13.30 \%)$ left dominant and $3(10 \%)$ codominant coronary vessels were found Hem cases. One (3.33\%) of HCM cases had myocardial bridging. Coronary artery stenosis were found in $5(16.67 \%)$ cases of HCM and among them, single vessel disease was present in 3 $(60 \%)$, double vessel disease in I (20\%) and triple vessel disease in I (20\%) cases.

HCM cases had significantly larger coronary artery dimension than control group and among the coronary arteries, proximal LAD (3.81 \pm 0.64 vs $2.49 \pm 0.61 \mathrm{~mm} . \mathrm{P}<$ $0.001)$, proximal $\mathrm{LCx}(3.29 \pm 0.46$ vs $2.39 \pm 0.60 \mathrm{~mm}, \mathrm{P}<0.001)$ and proximal RCA $(3.15 \pm 0.47$ vs $2.49 \pm 0.42 \mathrm{~mm}, \mathrm{P}<0.001)$. $\mathrm{LAD} / \mathrm{LCx}$ ratio was significantly higher in HCM cases than control ( $1.16 \pm 0.14$ vs $1.05 \pm 0.09, \mathrm{P}<0.001)$. HCM cases had significantly higher IVS/LAD ratio $(4.75 \pm 0.73$ vs $3.16 \pm 0.36, \mathrm{P}<0.001)$ and IVS thickness $(17.97 \pm 3.12 \mathrm{vs}$ $7.70 \pm 1.37, \mathrm{P}<0.001)$ than control.

\section{Conclusion:}

Coronary artery disease (CAD) associated with hypertrophic cadiomyopathy (HCM) is a complex clinical syndrome, difficult to diagnose clinically, that can reliably be recognized by coronary arteriography. Lesion of coronary artery plays an important role in the progression from hypertrophic cadiomyopathy to dilated cardiomyopathy. Increased coronary artery dimensions were observed in HCM but when analyzed with respect to regional ventricular thickness, these subjects demonstrated relative inadequate enlargement in coronary artery dimension.

\section{References:}

1. Akasaka T, Yokikawa Y. Phagis coronary flow characteristic in patients with hypertrophic cardiomyopathy. J Am Soc Echo 1994; 7:9-13.

2. Braunwald E, Hypertrophic cardiomyopathy continued progress. N Engl J Med 1989; 320:800-6.

3. Braunwald E. Lambrew CT, Rockoff D, Ross J Jr, Morrow AG. Idiopathic hypertrophic subaortic stenosis: I. A description of the disease based upon an analysis of 64 patients. Circulation 1964;30(Suppl IV): 3-217.

4. Brown BG, Bolson E, Frimer M, Dodge HT. Quantitative coronary arteriography: estimation of dimensions, hemodynamic resistance and atheroma mass of coronary artery lesions using the arteriogram and digital computation. Circulation 1977; 55:329-37.

5. Buchi M, Hess OM, Kirkeeide RL. Validation of a new automatic system for biplane quantitative coronary arteriography. Int J Card imaging 1990; 5:93-103.

6. Deligonal U, Roth R, kern MJ, Angiographic data. In: Kerm MJ, editor. The cardiac catheterization handbook. 2nd ed. St. Louis: Mosby-Year Book Inc., 1995: pp.266-375.

7. Deligonal U, Roth R, Flynn M. Arterial and venous access. In: Kern MJ, editor. The cardiac catheterization handbook. 2nd ed. St. Louis: Mosby-Year Book Inc., 1995:pp.45-7.

8. Haque KMHSS, Najimuddin K, Hossainn M. Evaluation of risk factors of ischemic heart disease in hospitalized patients. J Bangladesh Coll Phys Surg 1983;1:1-6.

9. Harjai KJ, Cheirif J, Murgo JP. Ischemia and atherosclerotic coronary artery disease in patients with hypertrophic cardiiopathy: a review of incidence, pathophysiological mechanism. clinical implications and management strategies. Coron Artery Dis 1996; 7:183-7.

10. Henry WL, Clark CE, Epstein SE. Asymmetric septal hypetrophy (ASH). Circulation 1973; 47:225-33.

11. Henry WL, Clark CE, Epstein SE. Idiopathic hypertrophic subaortic stenosis. Am J Cardiol 1975; 35:337-45.

12. Kaufmann P, Vassalli G, Lupi-Wanger S. Jenni R, Hess OM. Coronary artery dimensions in primary and secondary left ventricular hypertrophy. J Am Coll Cardiol 1996; 28:745-50.

13. Kimball BP, LiPreti V, Bui S, Wingle ED. Comparison of proximal left anterior descending and circumflex coronary artery dimensions in aortic valve stenosis and hypertrophic cardiomyopathy. Am J Cardiol 1990; 65:767-71.

14. klues HG, Roberts WC, Maron BJ. Anomalous insertion of papillary muscle directs in anterior mitral leaflet in hypertrophic cardiomyopathy, Circulation 1991; 1651-60.

15. Marian AJ, Roberts R. Recent advances in the molecular genetics of hypertrophic cardiomopathy. Circulation 1995; 92:1336-47.

16. Maron BJ. Asymmetry in hypertrophic cardiomopathy: the septal to free wall ratio revisited. Am J Cardiol 1985; 55:8358.

17. Maron BJ, Bonow RO, Cannon RO, Leon MB. Hypertrophic cardiomopathy interrelation of clinical manifestation, pathophysiology and therapy. N Engl J Med 1997; 316:7809.

18. Maron BJ, Gardin JM, Flack JM, Gidding SS, Kurosaki TT, Bild DE. Prevalence of hypertrophic cardiomopathy in a general population of young adults: echocardiographic analysis of 4111 subjects in the CARDIA Study. Coronary Artery Risk Development in (Young) Adults. Circulation 1995; 92:785-9. 
19. Maron BJ, Gottdiener JS, Arce J. Dynamic subaortic obstruction in hypertrophic cardiomopathy analysis by pulsed Doppler echocardiography. J Am Coll cardial 1985; 6:1-3.

20. Maron BJ, Harding AM, Spirito P, SAM of posterior mitral valve leaflet in hypertrophic cardiomopathy, Circulation 1983;68:282-93.

21. Maron BJ, Roberts WC, Epstein SE. Sudden death in hypertrophic cardiomopathy: a profile of 78 patients. Circulation 1982; 65:1388-90.

22. Mauser M. Combination of aneurysm and myocardial bridging at the same site of a coronary artery in a patient with obstructive hypertrophic cardiomopathy. Catheter cardiovas Interv 2000; 49:325-7.

23. Mc Donald KM, Mauner B, Permanent pacing as treatment for hypertrophic cardiomopathy. Am J Cardial 1991; 68:19810

24. Mc Kenna WJ, Camm Aj. Sudden death in hypertrophic cardiomopathy: assessment of patients at high risk. Circulation 1989; 80:1489-10.

25. Niwayama H, Morooka S, Takaoka N, Inagaki M, Yoshida H, Shukuya M, Doba N. Hypertrophic cardiomopathy associated with anomalous origin of the left coronary artery from the right sinus of Valsalva. Kokyu To Junkan 1991; 39:613-6.

26. Pollick C, Morgan CD, Gilbert BW, Muscular subaortic stenosis: the temporal relation between systolic anterior motion of the anterior mitral valve leaflet and the pressure gradient. Circulation 1982; 66:1087-91.

27. Schwartz K, Carrier L, Guicheney P, Komajda Male, Molecular basis of familial cardiomyopathies, Circulation 1995;91:53240 .

28. Shapiro LM, Zezulka A. Hypertrophic cardiomopathy: a common disease with a good prognosis: five-year experience of a district general hospital. Br Heart J 1983; 50:530-3.

29. Spirito P, Maron BJ. Relation between extent of left ventricular hypertrophy and diastolic filling abnormalities in hypertrophic cardiomopathy. J Am Coll Cardial 1990; 15:808-13.

30. Suter TM, Buechi M, Mess OM, Haemmerli SC, Gaglione A, Krayenbuchi HP, Normalization of coronary vasomotion after precutaneous transluminal coronary angioplasty? Circulation $1992 ; 85: 86-92$.

31. Watkins H, Thierfelder L, Anan R. Independent origin of identical $\beta$ myosin heavy chain gene mutations in hypertrophic cardiomopathy. Am J Hum Genet 1993; 53:1180-2.

32. Wingle ED, Rakowski H, Kimball BP. Hypertrophic cardiomopathy: clinical spectrum and treatment, Circulation 1995; 92:1680-5.

33. Yamada A, Nakamoto S, Sakamoto M, Matsumoto T, An autopsy case developing both marked stenosis of the coronary artery and dilated phase of hypertrophic cardiomopathy. Kokyu To Junkan 1993;41:689-92. 